\title{
GMR
}

\section{Migration and invasion enhancer 1 (MIEN1) is overexpressed in breast cancer and is a potential new therapeutic molecular target}

\author{
H.-B. Zhao ${ }^{1}$, X.-F. Zhang ${ }^{2}$, H.-B. Wang ${ }^{1}$ and M.-Z. Zhang ${ }^{1}$ \\ ${ }^{1}$ Department of Oncology, The First Clinical Hospital of Zhengzhou University, \\ Zhengzhou, Henan, China \\ ${ }^{2}$ Department of Pathology, Shangqiu Medical College, Shangqiu, Henan, China \\ Corresponding author: M.-Z. Zhang \\ E-mail: zhangmingzhi_mz@163.com \\ Genet. Mol. Res. 16 (1): gmr16019380 \\ Received September 23, 2016 \\ Accepted December 20, 2016 \\ Published February 8, 2017 \\ DOI http://dx.doi.org/10.4238/gmr16019380
}

Copyright (C) 2017 The Authors. This is an open-access article distributed under the terms of the Creative Commons Attribution ShareAlike (CC BY-SA) 4.0 License.

\begin{abstract}
Migration and invasion enhancer 1 (MIEN1) is a membrane-anchored protein that is highly expressed in various types of cancer, and is correlated with the PI3K/AKT pathway. The aim of this study was to investigate the expression of MIEN1 and its clinical pathological significance in breast cancer. We used immunohistochemical staining to examine the expression of MIEN1 in 40 samples of human breast cancer tissue and 10 samples taken from regions adjacent to normal breast tissue. The rate of detection of MIEN1 protein was $67.5 \%$, which was significantly higher than that in adjacent non-cancerous breast tissue $(0 \%, \mathrm{P}<0.05)$. The expression of MIEN1 correlated with age, World Health Organization grade, and lymph node metastasis, but not with tumor size or family history of cancer. KaplanMeier survival analysis showed that patients with positive MIEN1 protein expression had a lower overall survival rate than patients who did not express MIEN1. Downregulation of MIEN1 suppressed the expression of matrix metallopeptidase 9 by downregulating the
\end{abstract}

Genetics and Molecular Research 16 (1): gmr16019380 
expression of protein kinase B (also known as AKT) in breast cancer cells. Our results indicate that MIEN1 overexpression may facilitate migration and invasion in breast cancer, and MIEN1 is a potential molecular target for cancer chemotherapy.

Key words: MIEN1; Breast cancer; Cell migration; Cell invasion; Overall survival

\section{INTRODUCTION}

Breast cancer is a common malignant tumor in women, and migration and invasion are the main causes of early tumor dissemination. The aggressiveness of breast cancer is partially due to its intrinsic and extrinsic drug resistance to trastuzumab, which is a monoclonal antibody that interferes with the HER2/neu receptor (De Maria et al., 2005; Musolino et al., 2011). Therefore, there is an urgent need for new therapeutic targets and a better understanding of the molecular mechanisms underlying breast cancer.

Migration and invasion enhancer 1 (MIEN1), previously known as C35 or C17orf37, is a transforming oncogene that is involved in various types of cancers, and is located within the smallest region of amplification of the HER2 amplicon, between HER2 and GRB7 (Rajendiran and Vishwanatha, 2013). The chromosomal arrangement of the MIEN1 and HER2 genes is tail to tail (Evans et al., 2006; Katz et al., 2010). MIEN1 is a membraneanchored protein that is highly expressed in more than $60 \%$ of breast cancers, and contains a canonical immunoreceptor tyrosine-based activation motif (ITAM) sequence and a thioredoxin-like fold. ITAM-containing proteins can contribute to mammary epithelial cell transformation, and are closely associated with epithelial-mesenchymal transition (Grande et al., 2006). Recently, a study by Li et al. (2016) suggested that downregulation of MIEN1 by simvastatin inhibits the proliferation of colon cancer. However, the molecular mechanism by which MIEN1 influences apoptosis, proliferation, migration, and invasion in breast cancer remains unclear. In this study, we carried out immunohistochemical staining and shRNA targeting of MIEN1. Our objectives were to confirm the correlation between the expression of MIEN1 protein and clinical pathological characteristics in breast cancer, and to elucidate the underlying mechanisms whereby MIEN1 boosts the migration and invasion of breast cancer cells.

\section{MATERIAL AND METHODS}

\section{Patients and tissue specimen}

Forty breast-invasive ductal carcinoma tissue samples and 10 tumor-adjacent tissue samples were collected at the First Clinical Hospital of Zhengzhou University between January 2005 and July 2005. The patients were aged 31 to 72 (median age 46). None of the patients had undergone chemotherapy, radiotherapy, or immunotherapy before radical surgery. All tissue specimens were confirmed independently by two qualified pathologists without prior knowledge of the patient characteristics. We obtained an ethical approval statement from our hospital's Ethics Committee, and written informed consent from all participants.

Genetics and Molecular Research 16 (1): gmr16019380 


\section{Immunohistochemistry assay}

Goat anti-C35 (MIEN1) polyclonal antibody and a 3,3'-diaminobenzidine (DAB) staining kit were purchased from Santa Cruz Biotechnology, Inc. (USA). All samples were fixed with $4 \%$ formaldehyde, embedded in paraffin, and subjected to serial sectioning for histopathological diagnosis and immunohistochemical examination. We used the MaxVision two-step immunohistochemical method to detect MIEN1 expression. Consecutive 3- $\mu \mathrm{m}$ sections were deparaffinized, hydrated, and rinsed in distilled water. The samples were boiled in citrate buffer, $\mathrm{pH}$ 6.0, in a pressure cooker for $8 \mathrm{~min}$, cooled to room temperature, and washed four times with phosphate-buffered saline (PBS; pH 7.4) for 5 min. All samples were incubated with goat anti-C35 (MIEN1) polyclonal antibody (1:50 dilution) at $4{ }^{\circ} \mathrm{C}$ overnight. The next day, the samples were washed four times with PBS for $5 \mathrm{~min}$, and incubated with anti-goat IgG antibody for $1 \mathrm{~h}$. Afterwards, the samples were washed three times with PBS for $5 \mathrm{~min}$. The DAB reagent was used to stain the samples, which were examined using a light microscope. The samples were then rinsed in distilled water to terminate the reaction. PBS was used instead of the primary antibody as a negative control and a known sample was used as a positive control.

We performed the following scoring method to evaluate MIEN1 expression. Each sample was graded based on the average percentage of positive cells and the staining intensity in five areas (per x 100 field) at random. The intensity (S) was graded as follows: 0 (no staining); +1 (cells stained yellow); +2 (cells stained orange); and +3 (cells stained brown). According to the mean percentage $(\mathrm{P})$ of positive cells, the percentage scores were classified as: $0,<5 \%$ staining; $1,6-25 \% ; 2,26-50 \% ; 3,<51-75 \%$; and $4,>75 \%$. The final $\mathrm{H}$-scores were obtained using the equation: H-SCORE $=\square(\mathrm{S} \times \mathrm{P})$. The classification was as follow: scores of 0-1 were considered negative; scores of 2-4 points were considered weakly positive; scores of 5-8 points were considered moderately positive; and scores of 9-12 points were considered strongly positive.

\section{Cell culture}

Non-malignant MCF-10A cell lines and malignant MDA-MB-231 cell lines were preserved in our laboratory. Cells were cultured in Dulbecco's modified Eagle's medium/F12 (Sigma-Aldrich, St. Louis, MO, USA) supplemented with 5\% horse serum, 1\% penicillin/ streptomycin (Sigma-Aldrich), $0.5 \mathrm{mg} / \mathrm{mL}$ hydrocortisone (Sigma-Aldrich), $100 \mathrm{ng} / \mathrm{mL}$ cholera toxin (Sigma-Aldrich), $10 \mu \mathrm{g} / \mathrm{mL}$ insulin (Sigma-Aldrich), and $20 \mathrm{ng} / \mathrm{mL}$ recombinant human EGF (PeproTech, 100-15) in a $5 \% \mathrm{CO}_{2}$ incubator at $37^{\circ} \mathrm{C}$. The media were changed every 3 days and cells were passaged when they reached $65-80 \%$ confluence.

\section{In vitro transfection}

A C35 shRNA plasmid was designed for MIEN1. The C35 shRNA Plasmid (h) and support reagents were purchased from Santa Cruz Biotechnology, Inc. (Texas). In vitro transfection was carried out according to the manufacturer protocol. We prepared a $1.2-\mathrm{mg} / \mathrm{mL}$ siRNA solution $(100 \mu \mathrm{L})$ by mixing $50 \mu \mathrm{L}$ siRNA duplex solution and $50 \mu \mathrm{L}$ complexation buffer. We then brought the solution to room temperature, placed it in a $1.5-\mathrm{mL}$ tube, and immediately added diluted siRNA solution. We immediately vortexed the solution to ensure

Genetics and Molecular Research 16 (1): gmr16019380 
complexation, and added the cells. The transfection rates were measured by fluorescence microscopy.

\section{Quantitative reverse transcription polymerase chain reaction (qRT-PCR)}

Total RNA was extracted from cells using TRIzol reagent (Toyobo Co., Ltd., Shanghai, China). The ratio of optical density at $260 \mathrm{~nm}\left(\mathrm{OD}_{260}\right)$ to optical density at $280 \mathrm{~nm}\left(\mathrm{OD}_{280}\right)$ was over 1.7. Subsequently, the RNA molecules were reverse-transcribed into complementary DNA (cDNA) molecules using a PrimeScript ${ }^{\mathrm{TM}}$ RT Reagent Kit (TaKaRa Bio Inc., Osaka, Japan). qRT-PCR was carried out using SYBR Green master mix real-time core reagents (Toyobo Co., Ltd.) on an ABI 7500 system (Applied Biosystems) according to the manufacturer instructions. All primers and probe combinations were designed using Primer Premier 6.0 (Premier Biosoft, Canada), and were purchased from Sangon Biotech Co., Ltd., Shanghai, China. The primers for qRT-PCR were as follows: MIEN1-F: 5'-GCCATCCGAAGAGCCAG TA-3'; MIEN1-R: 5'-ATTACCGAGGCGAAGAGTGG-3'; AKT-F: 5'-TCGCTTCTTTGCCG GTATCG-3'; AKT-R: 5'-AGTAGGAGAACTGGGGGAAG-3'; Matrix metallopeptidase 9 (MMP-9)-F: 5'-GACTCCGTCTTTGAGGAGCC-3'; MMP-9-R: 5'-GAACTCACGCGCCAG TAGAA-3'; $\beta$-actin-F: 5'-AGAAAATCTGGCACCACACC-3'; $\beta$-actin-R: 5'-TAGCACAGC CTGGATAGCAA-3'.

The reaction solution comprised $6.4 \mu \mathrm{L}$ double-distilled $\mathrm{H}_{2} \mathrm{O}, 10 \mu \mathrm{L}$ SYBR Green Real-Time PCR Master Mix, $0.8 \mu \mathrm{L} 10 \mu \mathrm{M}$ primer $1,0.8 \mu \mathrm{L} 10 \mu \mathrm{M}$ primer 2 , and $2 \mu \mathrm{L}$ Template DNA. The cycling conditions were as follows: pre-denaturation at $95^{\circ} \mathrm{C}$ for $30 \mathrm{~s}$; 40 cycles of denaturation at $95^{\circ} \mathrm{C}$ for $5 \mathrm{~s}$, annealing at $65^{\circ} \mathrm{C}$ for $10 \mathrm{~s}$, and extension at $72^{\circ} \mathrm{C}$ for $15 \mathrm{~s}$; followed by melting curve analysis. All reactions were performed in triplicate, and the expression of mRNAs was normalized to that of the reference gene ACTB (which encodes $\beta$-actin). The relative quantification of mRNA within the samples was calculated using the $2^{-\Delta \Delta \mathrm{Ct}}$ method.

\section{Western blotting}

The concentration of total protein extracted from MCF-10A and MDA-MB-231 cells was determined using a BCA Protein Assay Kit (Pierce, USA). Equal amounts of protein were separated by $10 \%$ sodium dodecyl sulfate polyacrylamide gel electrophoresis and electrophoretically transferred to polyvinylidene difluoride membranes (Pierce) using a mini trans-blot (Bio-Rad Laboratories, Hercules, CA, USA). Goat anti-human C35 (MIEN1), AKT, MMP-9, and $\beta$-actin were purchased from Santa Cruz Biotechnology, Inc. The $\beta$-actin was used as an internal control. Electrochemiluminescence was carried out according to the manufacturer instructions and read with a ChemiImager 5500 imaging system (Alpha Innotech Co., San Leandro, CA, USA).

\section{Statistical analysis}

Data analysis was carried out using the Statistical Package for the Social Sciences (SPSS) software, version 17.0 (USA). Data analysis of the qRT-PCR results was carried out using a Mann-Whitney U-test. Possible associations between the positive expression of MIEN1 and clinicopathological parameters were determined using a chi-square $\left(\chi^{2}\right)$ test or

Genetics and Molecular Research 16 (1): gmr16019380 
Fisher exact test, and Kaplan-Meier survival analysis was conducted to compare the survival rates between two groups. Differences with a P value of less than 0.05 were considered to be statistically significant.

\section{RESULTS}

\section{Increased expression of MIEN1 in breast cancer}

We used immunohistochemistry to determine the level of expression of MIEN1 in breast cancer and adjacent normal tissues. We found predominant expression of MIEN1 in the cytosol with intense staining in the membranes of breast cancer cells (Figure 1A, B, C). Twenty-seven cases of 40 (67.5\%) showed positive expression. MIEN1 was not expressed in the adjacent normal breast tissue; there was a significant difference in expression between the breast cancer tissues and the adjacent normal tissues $(\mathrm{P}<0.05)$. The results show that MIEN1 is overexpressed in breast cancer.

A
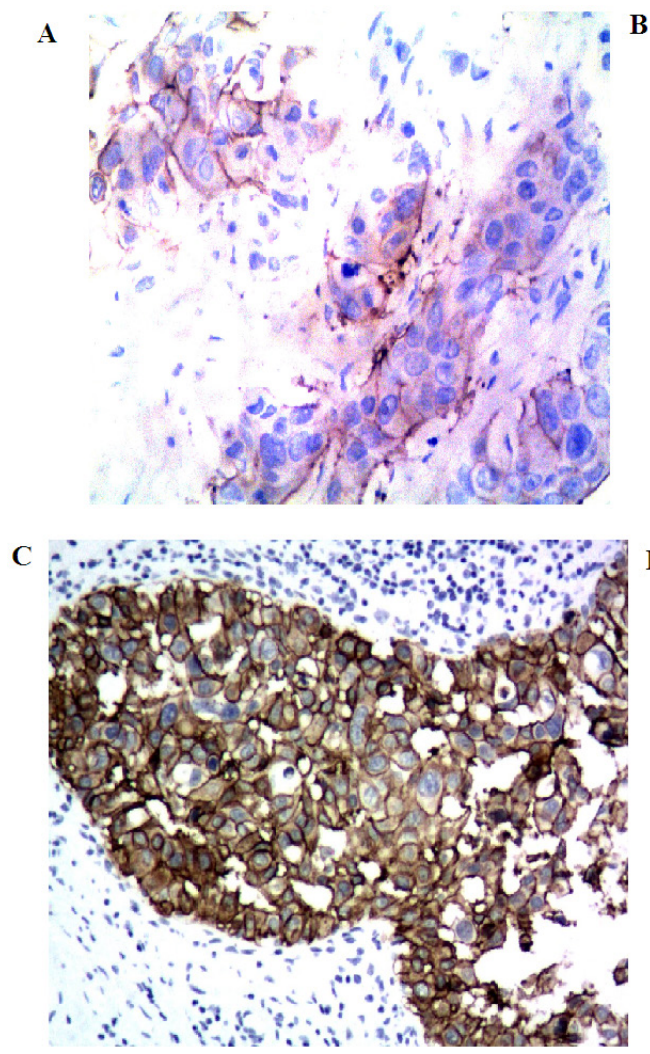

B

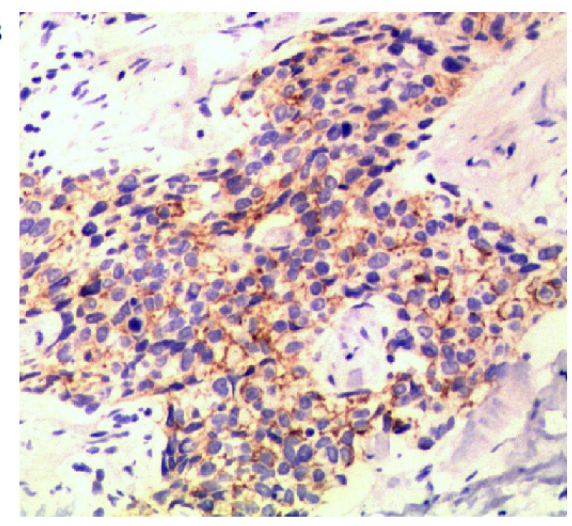

D

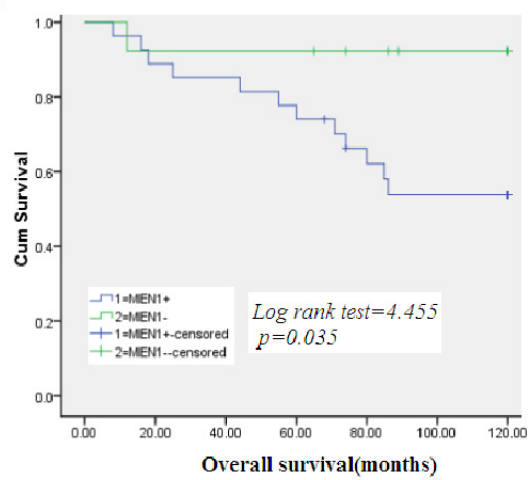

Figure 1. Expression of migration and invasion enhancer 1 (MIEN1) in breast cancer and its correlation with overall survival in all patients. A. Weakly positive expression of MIEN1 in breast cancer tissue (400X). B. Moderately positive expression of MIEN1 in breast cancer tissue (400X). C. Strongly positive expression of MIEN1 in breast cancer tissue (400X). D. Correlation between MIEN1 expression and overall survival in all patients. 


\section{Correlation between the expression of MIEN1 protein and clinicopathological characteristics}

The correlation between the expression of MIEN1 protein and clinicopathological characteristics was examined in the 40 breast cancer patients (Table 1). There were significant differences in MIEN1 expression with respect to age, World Health Organization (WHO) grade, and lymph node metastasis $(\mathrm{P}<0.05)($ Table 1$)$, but no significant differences were found in MIEN1 expression with respect to family history of cancer or tumor size $(\mathrm{P}>0.05)$.

\begin{tabular}{|c|c|c|c|c|c|c|c|c|}
\hline \multirow{2}{*}{\multicolumn{2}{|c|}{ Clinicopathological characteristics }} & \multicolumn{2}{|c|}{ All patients } & \multicolumn{2}{|c|}{ MIEN1 (N) } & \multirow[t]{2}{*}{$\chi^{2}$} & \multirow[t]{2}{*}{$P$} & \multirow[t]{2}{*}{$\mathrm{r}$} \\
\hline & & $\mathrm{N}$ & $\%$ & Positive & Negative & & & \\
\hline \multirow[t]{2}{*}{ Age } & $>46$ & 13 & 32.5 & 5 & 8 & \multirow[t]{2}{*}{7.403} & \multirow[t]{2}{*}{0.007} & \multirow[t]{2}{*}{$-4.30^{*}$} \\
\hline & $\leq 46$ & 27 & 67.5 & 22 & 5 & & & \\
\hline \multirow[t]{2}{*}{ Family history of cancer } & Yes & 7 & 17.5 & 4 & 3 & \multirow{2}{*}{0.415} & \multirow{2}{*}{0.519} & \multirow{2}{*}{-0.102} \\
\hline & No & 33 & 82.5 & 23 & 10 & & & \\
\hline \multirow[t]{2}{*}{ Tumor size, $\mathrm{cm}$} & $\leq 2$ & 36 & 90 & 26 & 10 & \multirow[t]{2}{*}{3.659} & \multirow[t]{2}{*}{0.056} & \multirow[t]{2}{*}{0.302} \\
\hline & $>3$ & 4 & 10 & 1 & 3 & & & \\
\hline \multirow[t]{3}{*}{ WHO grade } & I & 3 & 7.5 & 1 & 2 & \multirow[t]{3}{*}{12.263} & \multirow[t]{3}{*}{0.002} & \multirow[t]{3}{*}{$0.332 *$} \\
\hline & II & 22 & 55 & 20 & 2 & & & \\
\hline & III & 15 & 37.5 & 6 & 9 & & & \\
\hline \multirow[t]{2}{*}{ Lymph node metastasis } & Yes & 22 & 55 & 19 & 3 & \multirow[t]{2}{*}{7.930} & \multirow[t]{2}{*}{0.005} & \multirow[t]{2}{*}{$0.445^{*}$} \\
\hline & No & 18 & 45 & 8 & 10 & & & \\
\hline
\end{tabular}

$* \mathrm{P} \leq 0.001$.

Follow-up to our study ended in July 2015. The median overall survival time was 96 months $(95 \% \mathrm{CI}=84.7-107.9$ months $)$. We used the log-rank test to investigate cumulative survival in the breast cancer patients. The results indicate that positive or negative MIEN1 protein expression was associated with a significant difference in the overall survival of the patients (log-rank test statistic $=4.455, \mathrm{P}=0.035)($ Figure 1D).

\section{Breast cancer cells overexpressed MIEN1 and knockdown of MIEN1 decreased MIEN1 expression}

The results described above prompted us to determine whether MIEN1 is overexpressed in breast cancer cells. We examined MIEN1 mRNA expression in the breast cancer cell lines. We used cDNA from the non-malignant MCF-10A cell line as a control to quantify MIEN1 mRNA levels in the cell lines. Compared with the MCF-10A cells, qRT-PCR analysis showed that the expression of MIEN1 mRNA was significantly higher in the malignant MDA-MB-231 cells $(\mathrm{P}<0.05)$. The level of MIEN1 mRNA expression was lower in the transfected MIENsh cells than in the MDA-MB-231 cells. Compared with the MCF-10A cells, there was no significant difference $(\mathrm{P}>0.05)$ (Figure 2A).

\section{MIEN1 knockdown caused the downregulation of AKT and MMP-9 in breast cancer cells}

To elucidate the mechanisms by which MIEN1 promotes the migration and invasion of breast cancer cells, we investigated the expression of several key proteins in MIEN1 knockdown MDA-MB-231 cells. The knockdown of MIEN1 resulted in reduced mRNA 
levels of AKT and MMP-9 in MDA-MB-231 cells after MIEN-sh transfection (Figure 2B, 2C). These data show that MIEN1 knockdown inhibited cell migration and invasion in breast cancer cells by disrupting the AKT signaling pathway. Western blotting analysis confirmed the expression of AKT and MMP-9 (Figure 2D).

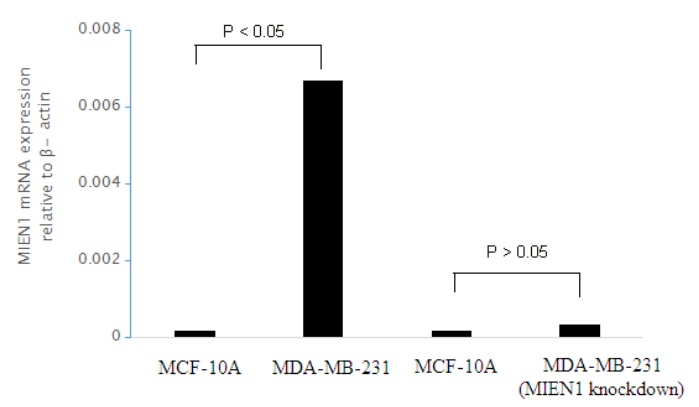

A

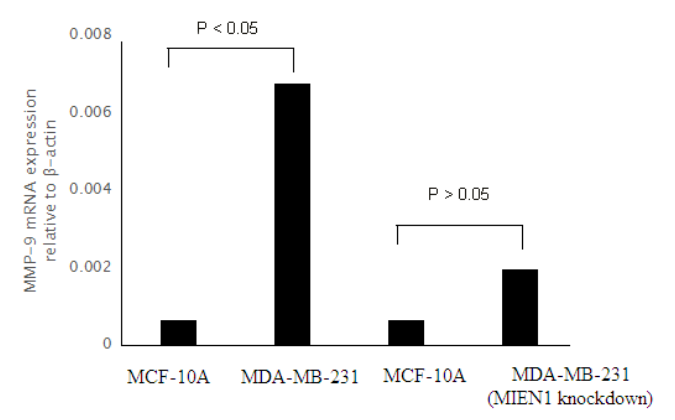

$\mathrm{C}$

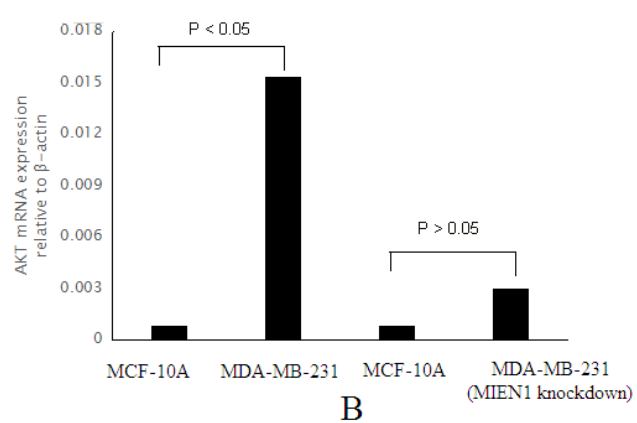

B

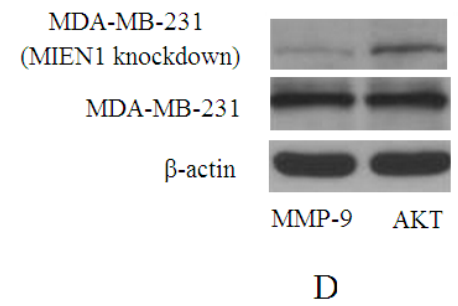

Figure 2. Expression of migration and invasion enhancer 1 (MIEN1) in breast cancer cell lines. A. mRNA levels of MIEN1 in MCF-10A and MDA-MB-231 cells (left, $\mathrm{P}<0.05$ ); mRNA levels of MIEN1 in MCF-10A cells and MDA-MB-231 cells after MIEN1-sh transfection (right, $\mathrm{P}>0.05$ ). B. mRNA levels of AKT in MCF-10A and MDA-MB-231 cells (left, $\mathrm{P}<0.05$ ); mRNA levels of AKT in MCF-10A cells and MDA-MB-231 cells after MIEN1-sh transfection (right, $\mathrm{P}>0.05$ ). C. mRNA levels of MMP-9 in MCF-10A and MDA-MB-231 cells (left, $\mathrm{P}$ $<0.05$ ); mRNA levels of MMP-9 in MCF-10A cells and MDA-MB-231 cells after MIEN1-sh transfection (right, $\mathrm{P}$ $>0.05$ ). D. Western blotting detection of AKT and MMP-9 protein in MDA-MB-231 cells and decreased AKT and MMP-9 in MDA-MB-231 cells after MIEN1-sh transfection.

\section{DISCUSSION}

Overexpression of MIEN1 protein is correlated with migration and invasion in various types of cancer cells (Slamon et al., 1987; Dasgupta et al., 2009). MIEN1 overexpression enhances the migration and invasion of tumor cells in prostate cancer (Dasgupta et al., 2009). In this study, we used immunohistochemical staining to investigate the expression of MIEN1 protein in breast cancer and adjacent normal tissues. We detected overexpression of MIEN1 protein in invasive breast cancer tissues, but did not detect MIEN1 in normal breast tissue samples. The overexpression of MIEN1 did not correlate with family history of cancer or tumor size. However, it was correlated with age, WHO grade, and lymph node metastasis. 
WHO grade and lymph node metastasis were positively correlated with MIEN1 expression, and MIEN1 expression was negatively correlated with age. This clinicopathological analysis indicated that expression of MIEN1 was negatively correlated with the patients' overall survival. The negative expression of MIEN1 protein was associated with a good prognosis in invasive breast cancer. An overabundance of MIEN1 could influence the migration and invasion of breast cancer cells.

RNA interference is a biological process in which RNA molecules inhibit target gene expression. It is now being widely used for target gene knockdown in the study of gene function (Agrawal et al., 2003; Liu et al., 2010). Semi-quantitative RT-PCR and western blotting analysis have been used to demonstrate that siRNAs expressed by psiRNA-C $35-1$ and psiRNA-C35-2 can effectively inhibit C35 mRNA and protein expression (Liu et al., 2010). The results of our qRT-PCR analysis were consistent with this finding.

The PI3K-AKT signaling pathway has been identified as one of the major factors in cancer. Therefore, we determined whether this signaling pathway is related to the biological functions of MIEN1 in breast cancer. Hsu et al. (2012) demonstrated that MIEN1 might have an important regulatory role in the phosphorylation of AKT, and phosphorylated AKT could stimulate a cascade of events that leads to proliferation, migration, and invasion. Studies have indicated that overexpression of NIEN1 activates the PI3K-AKT signaling pathway, upregulates downstream target genes by activating NF- $\mathrm{BB}$ signal transduction, and promotes the migration and invasion of prostate and ovarian cancer cells (Dasgupta et al., 2009; Leung et al., 2013). In this study, we found that MIEN1 knockdown MDA-MB-231 cells downregulated AKT and MMP-9 mRNA and protein. These results suggest that MIEN1 might promote the migration and invasion of MDA-MB-231 cells by activating different signaling pathways; this theory requires further investigation.

We showed that MIEN1 was overexpressed in breast cancer, and MDA-MB-231 cells were suppressed by inhibiting MIEN1 expression using shRNA. MIEN1 might play an important role in the progression of breast cancer, and is a potential molecular target for cancer chemotherapy. This study had some limitations: the sample size was low, and, owing to aberrant expression, variations might have existed in patient treatment strategies. Therefore, we will use a larger sample size to confirm our results.

\section{Conflicts of interest}

The authors declare no conflict of interest.

\section{REFERENCES}

Agrawal N, Dasaradhi PV, Mohmmed A, Malhotra P, et al. (2003). RNA interference: biology, mechanism, and applications. Microbiol. Mol. Biol. Rev. 67: 657-685. http://dx.doi.org/10.1128/MMBR.67.4.657-685.2003

Dasgupta S, Wasson LM, Rauniyar N, Prokai L, et al. (2009). Novel gene C17orf37 in 17q12 amplicon promotes migration and invasion of prostate cancer cells. Oncogene 28: 2860-2872. http://dx.doi.org/10.1038/onc.2009.145

De Maria R, Olivero M, Iussich S, Nakaichi M, et al. (2005). Spontaneous feline mammary carcinoma is a model of HER2 overexpressing poor prognosis human breast cancer. Cancer Res. 65: 907-912.

Evans EE, Henn AD, Jonason A, Paris MJ, et al. (2006). C35 (C17orf37) is a novel tumor biomarker abundantly expressed in breast cancer. Mol. Cancer Ther. 5: 2919-2930. http://dx.doi.org/10.1158/1535-7163.MCT-06-0389

Grande SM, Katz E, Crowley JE, Bernardini MS, et al. (2006). Cellular ITAM-containing proteins are oncoproteins in nonhematopoietic cells. Oncogene 25: 2748-2757. http://dx.doi.org/10.1038/sj.onc.1209296

Genetics and Molecular Research 16 (1): gmr16019380 
Hsu CH, Shen TL, Chang CF, Chang YY, et al. (2012). Solution structure of the oncogenic MIEN1 protein reveals a thioredoxin-like fold with a redox-active motif. PLoS One 7: e52292. http://dx.doi.org/10.1371/journal.pone.0052292

Katz E, Dubois-Marshall S, Sims AH, Faratian D, et al. (2010). A gene on the HER2 amplicon, C35, is an oncogene in breast cancer whose actions are prevented by inhibition of Syk. Br. J. Cancer 103: 401-410. http://dx.doi.org/10.1038/ sj.bjc. 6605763

Leung TH, Wong SC, Chan KK, Chan DW, et al. (2013). The interaction between C35 and DNp73 promotes chemoresistance in ovarian cancer cells. Br. J. Cancer 109: 965-975. http://dx.doi.org/10.1038/bjc.2013.397

Li M, Huang Y, Dong X, Wei Q, et al. (2016). Simvastatin downregulated C35 expression and inhibited the proliferation of colon cancer cells Lovo and HT29 in vitro. Biosci. Trends 10: 227-230. http://dx.doi.org/10.5582/bst.2016.01025

Liu QQ, Yin K, Zhu S, Zhang L, et al. (2010). Inhibition of C35 gene expression by small interfering RNA induces apoptosis of breast cancer cells. Biosci. Trends 4: 254-259.

Musolino A, Ciccolallo L, Panebianco M, Fontana E, et al. (2011). Multifactorial central nervous system recurrence susceptibility in patients with HER2-positive breast cancer: epidemiological and clinical data from a populationbased cancer registry study. Cancer 117: 1837-1846. http://dx.doi.org/10.1002/cncr.25771

Rajendiran S and Vishwanatha JK (2013). MicroRNA mediated regulation of a novel gene, MIEN1, in cancer metastasis. Cancer Res. 73: 5345. http://dx.doi.org/10.1158/1538-7445.AM2013-5345

Slamon DJ, Clark GM, Wong SG, Levin WJ, et al. (1987). Human breast cancer: correlation of relapse and survival with amplification of the HER-2/neu oncogene. Science 235: 177-182. http://dx.doi.org/10.1126/science.3798106

Genetics and Molecular Research 16 (1): gmr16019380 